\title{
A comunicação como aventura solipsística: sobre a "nova teoria" de Ciro Marcondes Filho
}

\author{
Communication as solipsistic adventure: on the "new theory" of Ciro \\ Marcondes Filho
}

Para Ciro Marcondes Filho $(* 1948-\uparrow 2020)$ : “Aquele que vive no meio de seus estudos e respectivas ocupações não percebe quando a morte o ganha. Quando o fim chega, toda a duração que passou desaparece. Resta porém o que conseguiu pela sua virtude e o que representou pelas suas iniciativas" (Cícero) $)^{1}$

\section{Francisco Rüdiger}

Doutor em ciências sociais pela Universidade de São Paulo. Professor das Universidades Católica e Federal do Rio Grande do Sul. Pesquisador do Conselho Nacional de Pesquisa Científica. Publicou recentemente "Síntese de História da Publicística - estágios reflexivos da ciência da comunicação pública alemã”.

\section{Submetido em 23 de Janeiro de 2020 Aceito em 07 de Maio de 2020}

\section{RESUMO}

Ciro Marcondes Filho gabaritou-se para propor uma "nova teoria" e, assim, tentar refundar os estudos de comunicação com trajetória de significativas contribuições à análise dos fenômenos de mídia. 0 presente estudo relata e examina em atitude

1 Remonta a 1986, quando, ainda cursando mestrado, fui por ele convidado a participar de Seminário Internacional na Universidade de São Paulo, o início de meu relacionamento intelectual com Ciro Marcondes Filho, a quem devo, mais que inspiração, incentivos decisivos em minha trajetória acadêmica. Desejo ver no artigo que, alinhavado há mais tempo, agora se publica minha homenagem de despedida ao trabalho de um intelectual para quem as verdadeiras relações humanas são sempre e, talvez, necessariamente raras, ao porem de lado convenções que ele, sendo um cavalheiro, não desmascarava, mas no íntimo sabia terem valor nenhum para quem almeja uma vida íntegra. Esboçado em conferência proferida durante o Seminário Comemorativo do Filocom, realizado na Escola de Comunicações da Universidade de São Paulo em 2010, o argumento foi, depois, resumido, primitivamente, no verbete "Ciro Marcondes Filho", por nós proposto e publicado na 2a edição (2014) do "Dicionário da Comunicação", concebido e editado pelo próprio Ciro para a Editora Paulus. Agradeço à equipe da Eco-Pós as providências que, à revelia do patético de sua desaparição, viabilizaram minha vontade de ver este artigo discutido academicamente por teórico inovador que, de minha parte, sempre teve amizade e admiração. 
ao mesmo tempo sistemática e crítica sua iniciativa. A conclusão é a de que, em vez de oferecer à teoria da comunicação um arcabouço conceitual para melhor esclarecer e, talvez, ajudar a desenvolver a pesquisa, seu empreendimento filosófico se esgota na pregação de uma doutrina de forte acento solipsístico.

PALAVRAS-CHAVE: Ciro Marcondes Filho; nova teoria da comunicação; teorias da comunicação; crítica.

\section{ABSTRACT}

Ciro Marcondes Filho qualified to propose what he calls a "new theory" and thus to reestablish the foundations of communication studies revealing a trajectory of significant contributions to the analysis of media phenomena. This paper reports and examines in a systematic and critical attitude that initiative. We conclude that, instead of offering a new and advantageous theoretical framework to clarify and perhaps help us to develop research in communication theory, his philosophical venture preaches in favor of a doctrine marked by strong solipsism.

KEYWORDS: Ciro Marcondes Filho; new communication theory; Communication theories; critique.

\section{Introdução}

Quer-se com este artigo relatar análise crítica, isto é, interessada em investigar os limites e pontos de ruptura, da "nova teoria da comunicação" apresentada, no transcurso dos últimos anos, por Ciro Marcondes Filho. Ao autor jamais faltaram credenciais para intervir nas discussões sobre os fundamentos teóricos dos estudos feitos na área de comunicação no Brasil. Em 40 anos de atividade, Marcondes construiu carreira marcada por importantes trabalhos sobre jornalismo, consumo, televisão, internet etc. De maneira inovadora, explorou em outros as relações entre mídia e cultura, teorizando sobre vários aspectos de seu modo de ser e impacto na sociedade. Amparando-se no criticismo pós-moderno, os coletivos que organizou identificaram o colapso das fórmulas de entender o real propostos pelas primeiras teorias a respeito.

Em seu ver, os esquemas baseados na distinção analítica tanto quanto enfática das figuras do emissor, do intermediário e do destinatário, provenientes 
da filosofia do sujeito, se tornaram anacrônicos. A comunicação de massas, midial, como ele diz em textos mais recentes, se confunde cada vez mais com a sociedade e, em meio a tanto, surge uma nova forma de agenciá-la, em que tudo aquilo se esfuma ao passar a funcionar conjunta e indistintamente (cf. Marcondes, 1996, p. 68-72; Marcondes, 2019).

Como Muniz Sodré, Fausto Neto e tantos outros colegas brasileiros, chegou o autor à conclusão de que "os processos de comunicação social são os novos estruturantes da vida em sociedade neste final de século [XX]" (Marcondes, 1998, p. 105). A tecnologia eletrônica tomou o lugar do trabalho como força determinante do social, abrindo-nos situação "ordenada por princípios até então estranhos e que não guardam analogia com nenhuma outra época". (Marcondes, 1998, p. 105).

Dissera ele ao estudar a notícia que, sendo a comunicação mera "forma de relacionamento humano", a teoria a respeito necessariamente precisaria provir dos "conhecimentos já desenvolvidos nas ciências sociais", se era para ela ter "bases sólidas e alicerçadas": estas faltariam à suposta "ciência" da comunicação (Marcondes, 1986, p. 9-10). Vencido um decênio, a perspectiva foi reformulada. "A ciência da modernidade, inclusive os desenvolvimentos da sociologia, da antropologia, da ciência política e das filosofias clássico-idealista e marxista", irremediavelmente associada a uma "visão de mundo triunfalista", viu-se arruinada por novo contexto, levando-nos a ter de repensar o estudo da teoria da comunicação como “campo específico de trabalho” (Marcondes, 1998, p. 106).

0 processo de transformação em nossa vida acionado pelo progresso tecnológico conduz ao sucateamento do pensamento moderno e à esclerose do discurso científico que orientou a pesquisa na comunicação até o momento. A criação de novas bases epistemológicas virou tarefa urgente numa realidade que parece invalidar os referenciais de conhecimento disponibilizados pelas velhas disciplinas. A surpresa se instala no momento em que, passo seguinte, apresentando as bases conceituais e metodológicas para a criação uma teoria da 
comunicação para a era tecnológica, o autor recorre ao subjetivismo ingênuo e à compreensão provinciana do trabalho acadêmico para desenvolver sua argumentação.

Perante o fracasso dos métodos de apreensão totalizadores, afirma o pesquisador, os métodos parciais de abordagem da realidade, conforme se pode aprendê-los através da arte e da literatura, revelar-se-iam doravante mais promissores, visto "darem espaço ao novo em seu nascedouro, sem ignorá-lo ou excluí-los por ser destoante" (Marcondes, 1998, p. 78). A crise dos paradigmas que se instalou nas ciências humanas em meio às circunstâncias pós-modernas nos força a procurar alternativas, se é para manter a validade e fazer avançar os estudos de comunicação. Os esquemas teóricos das ciências sociais se tornaram viciados e estão sendo ultrapassados, não têm mais como dar conta sequer da realidade dos meios de comunicação, convertida em uma espécie de contínuo atmosférico, que escapa à abordagem empírica e analítica, visto ser, este contínuo mesmo, sua condição de existência.

Destarte, a saída para este impasse estaria em repensar a comunicação humana como um todo e, com base nos seus resultados, tentar elaborar um novo método para estudá-la, visto, em sua opinião, este ser "certamente o problema filosófico mais sério com o qual o mundo hoje se depara" (Marcondes, 2010a, p. 66). Apesar de haver estratégias de resistência ao sistema e não faltarem contradições em seu interior, estão com a razão todos estes que, mais ou menos precisamente, reconhecem nossa caída em uma sociedade tecnológica marcada pela reificação e o automatismo e da qual não há saída senão por implosão (Marcondes, 2018, p. 123-140). Os aparatos midiais e as mensagens em massa se tornaram nossa realidade, um sistema onipotente de dimensões planetárias, mas no qual, entretanto, existem poros, por onde as singularidades nele capturadas respiram e, eventualmente, experimentam a comunicação.

A contemporaneidade evidencia um flagrante paradoxo epistemológico: enquanto a comunicação é campo emergente que habita todos os espaços e 
levanta indagações e questões absolutamente atuais, carentes de trabalhos investigativos imediatos, são os saberes constituídos em outros contextos e em outras épocas, que atendiam a demandas sociais outras, que se colocam na condição de estudá-los. Agora, é preciso virar a mesa, dotar os estudos comunicacionais stricto sensu da precedência que lhe cabe. A hora é de nos dedicarmos aos fenômenos comunicacionais e à sua emergência como o grande fenômeno da contemporaneidade com estatuto de campo próprio e autônomo. (Marcondes, 2014a, p. 70).

Disso tudo, procura-se dar conta sistematicamente o vasto e ambicioso projeto desenvolvido pelo autor na obra em vários volumes intitulada "Nova Teoria da Comunicação". A premissa dela é a de que se pode agregar todos os fenômenos de comunicação humana em um único e mesmo paradigma. "Acreditase que a comunicação seja a mesma, aconteça ela entre duas pessoas que se encontram na rua ou em grande escala, quando assistem ao noticiário jornalístico, à novela de televisão ou trocam mensagens [pela internet]”. (Marcondes, 2010b, p. 7).

Desejamos no que segue submeter este projeto a escrutínio imanente visando avaliar suas pretensões, por meio de cuidadosa análise de seus fundamentos. 0 argumento mostrará que, à luz de suas próprias referências epistemológicas, são especialmente problemáticas as ambições da "nova teoria" no sentido de refundar os estudos de comunicação.

\section{Relato da obra}

Parte o autor da premissa de que "a comunicação pertence, em primeiro lugar, ao campo da filosofia e somente depois aos campos derivados da linguística, semiologia, semiótica e das teorias gerais dos símbolos" (Marcondes, 2004, p. 11). 0 estudo dos fenômenos comunicacionais deve ser distinguido daqueles que, embora costumem ser tomados por tais, não são, de fato ou em essência, comunicacionais (Marcondes, 2018). Os pesquisadores e estudiosos da área desconhecem o verdadeiro estatuto teórico da categoria, por terem se prendido a 
uma visão dependente das ciências humanas. As escolas de comunicação restringem seu interesse ao estudo da comunicação mediada, deixando de fora as situações triviais e cotidianas, mas também os processos comunicacionais que ocorrem, por exemplo, através das artes e da literatura. A proposta da nova teoria confronta esta linha de ação, investindo na formulação de uma ontologia e, agregada a esta, uma nova epistemologia para a comunicação em que o foco estaria na comunicação mesma, em vez das suas circunstâncias tecnológicas, políticas, sociológicas etc.

A ontologia concentra-se na caracterização daquilo que se convencionou chamar de 'comunicação', tarefa esta que recebeu pouco interesse dos estudiosos do campo. Ao contrário, sempre se trabalhou como se a comunicação fosse algo óbvio, que não precisasse de definição. (Marcondes, 2010b, p. 8).

Marcondes apresenta suas ideias como proposta revolucionária interessada em construir um saber específico e possuidor de área de estudo própria. A comunicação, conforme entendida pelo senso comum e veiculada pela mídia, é uma farsa, um engano (Marcondes, 2004b). Procedendo à vasta varredura do pensamento humano, incluindo o dos antigos egípcios e chineses, procura o autor explicitar a "questão comunicacional", para, em seguida construir um novo conceito a respeito. A conclusão deste extenso trabalho em sua primeira e maior parte é a de que a comunicação só viria a revelar sua natureza em meados do século passado, quando os proponentes do pensamento cibernético e seus epígonos chegaram ao entendimento de que "a comunicação não existe, é algo impossível, ou então improvável (Luhmann)"(Marcondes, 2010a, p. 10).

Antes disso, nota o autor, no entanto, houve quem pôs em marcha a pesquisa a seu respeito, chegando-se por esta via, para o espanto do leitor, em Edmund Husserl. Chaim Samuel Katz havia cogitado, décadas antes, a possibilidade de buscar no pensamento daquele último meios para fundamentar teoricamente o conceito de comunicação em bases fenomenológicas. Ao final, contudo, concluiu que a equiparação da categoria à noção de intersubjetividade leva a uma 
transcendentalização das pretensões do discurso filosófico no sentido de legislar sobre o saber em termos absolutistas (cf. Katz, 1972; cf. Scherer, 1971, p. 76-96).

Ignorando esta possibilidade, Marcondes retomou em chave radicalmente distinta o projeto inicialmente proposto por Katz. Para ele, o filósofo alemão abriu espaço para pensar a comunicação como evento, em vez de estrutura; como algo estético, em vez de lógico. "Husserl foi inegavelmente o fundador da pesquisa da comunicação humana, da investigação da comunicação como um acontecimento que nos abate, que nos atropela, que nos transforma [...]" (Marcondes, 2010a, p. 311).

Teria surgido com ele a proposição para entender a comunicação humana como algo raro, capaz de nos proporcionar uma nova ontologia, ancorada na figura do acontecimento, já que, segundo o brasileiro, o correlato epistemológico deste entendimento seria um modelo de investigação em que ela, a comunicação, é olhada como "algo que pode ocorrer ou não ocorrer, e que, de qualquer forma, quando ocorre, altera os padrões anteriores [da percepção individual]" (Marcondes, 2010a, p. 10).

Em Marcondes, Merleau-Ponty, Henri Bergson, Emanuel Levinas e Martin Buber, apesar de considerados, apenas forneceriam contribuições complementares. 0 Círculo Cibernético do período pós-Guerra, por sua vez, meramente as retomaria, abrindo espaço para Maturana e Bateson. Em última análise, todos limitaram-se a reiterar que o fenômeno comunicacional tem características moventes e imprevisíveis, em permanente transformação, cuja observação se constrói e se esgota em sua ocorrência, exigindo-nos, pois, o desenvolvimento de uma nova metodologia.

[A nova teoria, levada à prática, significa uma] pesquisa que se faz vivenciando o próprio fato comunicacional, fazendo uma imersão nele, sentindo seus efeitos, observando as reações dos outros, tomando pé de todo o clima que envolve o fenômeno, seja um concerto de rock, uma vibração coletiva e nacional num jogo de copa do mundo, uma notícia trágica da política, um sequestro com reverberações em toda a imprensa. (Marcondes, 2013, p. 10). 
Marcondes ampara o método na premissa heraclitiana de que "o mundo é permanentemente movimento" e, portanto, de que, inseridos nele, "devemos pensar em movimento, produzir teorias 'no durante', sugerir descrições e constatações que considerem a provisoriedade do saber" (Marcondes, 2010a, p. 247), em vez de tentar determiná-lo de uma vez por todas com base na aplicação reiterada de uma metodologia de estudo, oriunda do logocentrismo ocidental, a julgar por Jacques Derrida. Apoia-se o autor em Levinas para defender que "está na minha relação com o outro, com sua estranheza, com sua impenetrabilidade, a base para a constituição de um novo conceito de comunicação [humana]". (Marcondes, 2010a, p. 12).

Significa, no argumento, que a comunicação humana não se confunde com o processo de transmissão de informações ou com as significações que se pode ou não tirar de um material simbólico. A comunicação deve ser vista como um evento que, raro e sempre único, irrepetível, "nos faz pensar nas coisas, nos outros, em nós mesmos, na nossa vida" (Marcondes, 2010a, p. 22).

Retomando o principal da "Crítica do Juízo" (1790), cuja leitura, nos parece, está no centro de todo o empreendimento e, como tal, dispensaria inúmeras referências autorais feitas em sua opera magna, Marcondes postula que a comunicação é uma experiência que se aproxima e virtualmente se confunde com a relação estética que podemos entreter com o mundo, como, procedendo transcendentalmente, havia pensado Kant. O "acontecimento" que seria a comunicação possui um caráter absolutamente diferente da simples fala e do mero se informar, ao mesmo tempo que ultrapassa a compreensão imediata do significado de uma manifestação dada à experiência.

A comunicação [humana] realiza-se no plano da interação entre duas pessoas, nos diálogos coletivos onde esse novo tem chance de aparecer, onde $\mathrm{o}$ acontecimento provoca o pensamento, força-o, onde a incomunicabilidade é trincada e criam-se espaços de interpenetração. Mas ocorre igualmente nas formas sociais maiores de contato com objetivos, especialmente com objetos culturais das produções televisivas, 
cinematográficas, teatrais, nos espetáculos de dança, nas performances, nas instalações, na possibilidade de criação de situações similares, inclusive em ambientes de relacionamento virtual. (Marcondes, 2010a, p. 23).

Marcondes condena os dicionários por definirem a comunicação humana como troca de informações, vista a conveniência de não a confundirmos com os sinais em que ela eventualmente tem base, da matéria sociotécnica que lhe fornece o ambiente. A comunicação não é algo material: trata-se de uma sensação, experiência inefável, que em si mesma não se confundiria com o sinal físico em que se apoia. A comunicação, contudo, também não é um processo estruturado pela linguagem, se entendermos por tal um movimento costumeiro, contínuo e linear de geração e compartilhamento de significação. A comunicação é um acontecimento fulgurante, único e singular, de caráter extralinguístico, que irrompe em meio à interação humana e suas formas de instituição.

“O acontecimento [da comunicação humana] é, não por acaso, [categoria] central nos estudos [a respeito]" (Marcondes, 2010a, p. 64). Como tal, todavia requer o corpo, se se efetiva, na medida em que o impacta e, como que por mágica, nos dilui no outro ou na coisa que o provoca. A comunicação é experiência total e única, em que os participantes, sejam um ou vários, sentem e, assim, modificam, ainda que minimamente, seu modo de ser.

As comunicações em massas, ao contrário, criam uma situação em que ninguém experiência mais nada, visto todos tendencialmente partilharem das mesmas sensações e conhecimentos. A oportunidade da nova teoria da comunicação está no fato desta situação, no entanto, comportar frestas e dar margem a vazamentos. 0 problema das comunicações em massa é intrínseco às formas ritualizadas de interação humana e não surgiu em nossa época, mas é certo que dentro dela se agravou, ajudando a criar as condições de possibilidade para seu entendimento ao gerar angústia.

A sociedade da informação cerceia as condições favoráveis à ocorrência da comunicação. As singularidades, no entanto, seguem se fazendo presentes na 
percepção que ocorre à margem da cultura midiática. As pessoas não são totalmente capturadas nela; apesar de tudo, conservam em seu poder a intuição sensível, através da qual não se fecha a possibilidade de descobrir outros caminhos, abrem-se poros, pelos quais eventualmente algo novo acontece, dando sinal da comunicação propriamente humana.

0 verdadeiro encanto em que ela consiste não acontece com o consumo de produtos midiáticos ou nossa absorção pelo seu aparato tecnológico, mas quando, em meio a tanto, algo nos toca, perturba nosso ser e em alguma medida nos modifica. A plenitude da comunicação se verifica, portanto, nas situações de bilateralidade, quando não apenas acolho o outro, mas este acolhe a mim, provocando uma apreciação recíproca não como entendimento, mas mistério da diferença (Marcondes, 2010a, p. 43).

Dewey expressa em juízo experiência que Marcondes, à sua maneira, descobriu e tomou para si, ao postular que:

Dentre todas as realizações, a comunicação é a mais notável. Trata-se de um prodígio, diante do qual a transubstanciação se torna pálida, que as coisas passem a ser capazes de transferir-se do plano das impressões externas para o do seu desvelamento para o homem, e assim para si próprias; que o resultado da comunicação passe a ser a participação e o ato de compartilhamento. Quando ocorre o comunicar-se, todos os eventos da natureza tornam-se sujeitos a reconsideração e a revisão. (Dewey, [1915] 1974, p. 187).

Para o brasileiro, "o acontecimento comunicacional tem sua existência, seu efeito e sua força na fração de tempo exata de sua realização" (Marcondes, 2010a, p. 91). A comunicação é o efeito momentâneo e inusitado da convergência de várias linhas intencionais, só podendo ser conhecida na brevidade de sua própria ocorrência. $\mathrm{O}$ fato tem seu instante oportuno no encontro único e acidental de todas as causas favoráveis e, portanto, jamais pode ser capturado positivamente. Os estudos posteriores a seu acontecimento, sejam eles quais forem, não são por isso, segundo o autor, “estudos de comunicação” (Marcondes, 2010a, p. 91). 
Marcondes passa por alto o conhecimento histórico e a teoria social ao endossar acriticamente o relato deleuziano sobre a origem do mundo, para explicar que "a linguagem surge do atrito entre a palavra e as coisas (entre proposições e corpos)" (Marcondes, 2010a, p. 82), embora subscreva o entendimento antropológico e subjetivista de que "a ordem é uma criação humana", que "reflete a disposição de espírito daquele que a identificou ou preconizou” (Marcondes, 2010a, p. 215).

A "racionalidade simplista", como ele diz, teria ignorado o principal ao tratar do assunto em juízo nestas páginas; isto é, o princípio heraclitiano de que "as coisas acontecem somente uma vez, não há reconstrução, nem recuperação" (Marcondes, 2010a, p. 92). 0 método de recomendável para tratar do assunto não é, portanto, o das ciências humanas: consistiria em apreender a comunicação "como fenômeno que ocorre enquanto o estamos vivendo". A racionalidade complexa é também a mais simples: "ela acompanha nossa vida, é paralela, contígua, sincrônica [à existência]" (Marcondes, 2010a, p. 92). O fenômeno é captado de uma única e só vez, no momento em que ocorre, ou pode ser dado como perdido ou prevenido: se procurarmos trabalhar com causas determinantes ou efeitos posteriores, já não se trata de um "estudo comunicacional" (Marcondes, 2010a, p. 93).

Marcondes deseja revolucionar nossa maneira de pensar, propondo que se abandone o cartesianismo, com sua ideia de análise de um objeto supostamente fixado desde sempre. A comunicação deve ser vivenciada em sua irrupção, para que possa nos dar acesso ao novo. Com ela, o estudo coincide com a experiência de um efeito que nos altera, todo o método se resumindo em "permitir que sua força e energia nos invadam e provoquem em nós seus efeitos" (Marcondes, 2010a, p. 94). A epistemologia que lhe é subjacente supera a relação sujeito e objeto, ao experimentar uma comunicação cujos efeitos se sentiriam numa mudança de ver o mundo para, depois, irremediavelmente desaparecerem . 


\section{Fenomenologia solipsista}

Passando ao comentário, convém, em primeiro, dizer que "Nova Teoria da Comunicação" é obra superlativa, leitura que exige paciência, dada as repetições e estilo. O primeiro volume apresenta resumidamente suas principais teses e referências. 0 último tomo do terceiro detalha aquelas primeiras, sem realmente acrescentar às suas conclusões. Nos cinco livros restantes, o conteúdo é formado por notas de estudo, que podem ser lidas independentemente. Os argumentos que cada um defende são interpostos ao fim dos seus blocos formadores. A reiteração de ideias ao longo dos vários volumes, parece-nos, em geral pouco acrescenta ao argumento central. Valeria, talvez, tê-lo também apresentado em um único, visando facilitar o acesso do leitor às teses pretendidamente mais originais. 0 autor relata e polemiza com autores e ideias cuja relevância na construção de seu projeto, às vezes, sequer se entrevê, visto não tratarem da comunicação social humana, quando não são hostis ao próprio emprego do conceito de comunicação (caso, por exemplo, da Escola de Frankfurt).

A pergunta com base na qual se desenvolve a investigação é: até que ponto, de fato, nós, seres humanos, comunicamos (Marcondes, 2007)? As conclusões da revisão bibliográfica do autor se baseiam na premissa metafísica de que "o mundo é permanentemente movimento". A proposta para tratar do assunto que delas emerge é a de que, inseridos nele, "devemos pensar em movimento, produzir teorias 'no durante', sugerir descrições e constatações que considerem a provisoriedade do saber" (Marcondes, 2010a, p. 247).

Disso tudo, no entanto, resulta, em nosso ver, uma doutrina esotérica, de corte arbitrário e feições dogmáticas. Marcondes nos martela a ideia de que, em nossas conversas, como diante da televisão ou lendo jornais, geralmente não há comunicação. As pessoas trocam mensagens e sinalizam informações, mas continuam as mesmas: nada se altera, tudo segue igual, mas como saber que é assim?

Dossiê Crise, Feminismo e Comunicação - https://revistaecopos.eco.ufrj.br/

ISSN $2175-8689$ - v. 23, n. 3, 2020

DOI: 10.29146/eco-pos.v23i3.27433 
Qual é a base para o autor afirmar que a comunicação é rara, embora às vezes aconteça? Trata-se de hipótese, dogma ou impressionismo? A nova teoria tem critérios intersubjetivos de pesquisa, ou é a prescrição para observar uma experiência possível ditada a uma comunidade, no caso, a dos comunicólogos, por um guru privilegiado? Caso haja critérios, isto é, sendo categorial, como se faz para que eles não contradigam sua afirmativa de que a comunicação é sempre singular? A certeza que, no curso da vida, certos eventos, ou um único, me fazem ter de eu, ainda que teoricamente, saber o que é a comunicação basta para tanto? Que eu, convicto, afirme ser amo da natureza e senhor do universo me torna tal coisa? Afirma-se que:

A comunicação só é possível com a alteridade. Mas não com qualquer alteridade. É preciso que se trate de uma alteridade radical. De um outro que não está lá apenas como outro, mas que se mantenha estranho em sua incapturabilidade, em sua eterna fuga. (Marcondes, 2018, p. 55).

Quem e como determina, porém, que uma alteridade é radical o bastante para ensejar a comunicação? Fora de uma comunidade iniciática, como se pode aferir e, assim, saber que, numa relação humana, o outro se mantém estranho?

Marcondes carrega demais no argumento, ao sugerir que as resistências à sua teoria se originam do fato dela ser nova e revolucionária, sem se questionar se isso não decorre do fato dela ser frágil e falaciosa, ou não interessar a quem, no estudo, foca nos fenômenos de mídia ou trabalha com outro conceito, talvez menos dogmático e subjetivista, de comunicação humana. 0 apoio documental, note-se, nada decide aqui, se é que tem pertinência em relação ao assunto, porque haveria outro, talvez muito mais pertinente ao assunto, dizendo que é pura e simplesmente distinto o interesse dos estudiosos dos fenômenos de mídia.

Para o autor, a comunicação é o que acontece de uma única vez (chegando ao extremo de afirmar que "é mistério, algo insondável" (Marcondes, 2018, p. 20). Sendo tal, jamais se repete, portanto - mas qual é o critério para estabelecer este juízo, se isso só se ilumina para o que trabalha com a nova teoria e, via de regra, só 
ocorre na sua própria experiência? Qual é o critério para dizer que estamos diante de um acontecimento comunicacional, e não perante outro qualquer, numa situação mundana? Em sendo comunicacional, que indicadores, além da intuição, permitem identificar seu começo, seus contornos e seu término? Ou nada disso mais importa, fica tudo a cargo de nossas intuições, se não de nosso arbítrio e idiossincrasia? Neste caso, falar sobre "saber comunicacional" visa algo mais que formar uma seita iniciática?

A comunicação, reza a nova doutrina, não pode ser compartilhada, muito menos traduzida ou representada, salvo em uns raros casos de bilateralidade, que o autor postula em abstrato, e nós supomos que, vindo a ocorrer, se daria sobretudo, entre teóricos marcondianos, visto que, na situação, outros investigadores poderiam identificar experiências distintas. 0 autor não cogita que, consideradas únicas e irrepetíveis, as ocorrências pelas quais se interessa possam ser outras, que não é preciso relacioná-las à comunicação, salvo no caso de um juiz monocrático e privilegiado lhes prescrever tal determinação categorial. A nova teoria deseja, mas de fato não está a salvo da filosofia do sujeito: pelo contrário, ela a radicaliza ${ }^{3}$.

Marcondes se entrega à sua criação com paixão arrebatadora, o que às vezes pode ser bom na vida íntima, mas não deveria servir de fundamento epistemológico para uma causa comum. Deseja ele pensar que, com sua obra, “o pensamento se dedica, talvez pela primeira vez, ao estudo da comunicação stricto sensu" (Marcondes, 2010a, p. 274). Qual é, no entanto, fora uma definição prévia e arbitrária da própria coisa, a força e propriedade dos argumentos que lhe permitem afirmar que a comunicação nunca foi estudada como deveria e que só pela via que ele descobriu e indica chegar-se-ia à sua essência?

30 endosso acrítico à metafísica psicologista é, neste contexto, apenas detalhe: a nova teoria pretende "estudar como a mente das pessoas reage ao receber este volume fantástico de excitações externas [dado pelo mundo midial]", almeja estudar "o que ocorre no interior de cada um de nós quando nos deparamos com um fato comunicacional” (Marcondes, 2013, p. 10).

\section{Dossiê Crise, Feminismo e Comunicação - https://revistaecopos.eco.ufrj.br/}


A comunicação, teoriza, não é um processo corrente, que pode ser estudado de maneira metódica e sistemática, ainda que explorando múltiplas problemáticas em distintos contextos. 0 fenômeno é função de algo que, vez por outra, acontece ao sujeito, independentemente de nossa intenção e dos nossos instrumentos. A teoria se limita a nos advertir para os termos de sua ocorrência na percepção do interessado.

Apreender [a comunicação] está vinculado à subjetividade do pesquisador, que será legitimada ou não, não pela base empírica comum às pesquisas dedutivas convencionais, tampouco pelo método indutivo da iteração ou repetibilidade dos fenômenos, mas pelo fato de outros [os leitores] se reconhecerem naquilo que foi descrito, corroborarem as impressões, acatarem o exposto como digno de ser acreditado. (Marcondes, 2014b, p. $342)$.

À parte a referência a um empirismo cuja presença na área, entre nós, brasileiros, ainda é pequena, o trecho põe na conta da crença e simpatia alheia a validação de um saber cujo cunho único e inefável, salvo milagre produzido por uma escrita sedutora, provavelmente lhe condena à indiferença - visto sua ênfase no vinculo idiossincrático e necessidade de amparo, talvez o autor não tenha notado, no apelo carismático e capacidade de indução que os promotores da nova teoria podem invocar em seu proveito (Marcondes, 2010c).

De acordo com a proposta, o estudioso da comunicação depende de que os sujeitos envolvidos, a começar pelo flâneur em que o pesquisador mesmo se tornou, definam o que ocorre como sendo ou tendo a ver com comunicação, visto que não sendo assim, o evento poderia ser qualquer outro: um êxtase, um pavor, uma decepção, uma alegria, etc. Logo não surpreende que, em princípio, o objeto da investigação seja preferencialmente seu próprio responsável, quer individualmente, quer formando grupo capaz de se induzir mutuamente (cf. Marcondes, 2015). Pressente-se que, assim, fica menor o perigo de, na falta de referência à "comunicação" por parte do informante, o estudioso se expressar em seu nome, revelar-se maior conhecedor do que o informante mesmo acerca de uma experiência que, entretanto, pertence apenas ao investigado. 
Marcondes parece cego para o fato de o risco de o pesquisador falar de maneira arbitrária e/ou irrelevante sobre si mesmo ou sobre o outro não é de modo algum prevenido, estando descartada qualquer possibilidade de mediação metódica e intersubjetiva em sua teoria. Para ele, o pesquisador "observa a realidade do fenômeno, ele o acompanha do início ao fim, descrevendo sua trajetória, as forças que ele mobiliza e as repercussões que são sentidas na esfera pública, evidenciada na expressão nas ruas [...]" (Marcondes, 2012, p. 773).

Noutros termos, reporta a esmo o que está acontecendo no contínuo atmosférico mediático do momento, como se este esgotasse a realidade, para, de súbito, talvez descobrir que, em um ponto imprevisível e incerto, algo relacionado àquele contínuo, não se sabe, já que não há critério guiando a observação, seja, intra ou empaticamente, acompanhado até eventualmente gerar uma experiência única e extraordinária, que todavia será classificada genericamente como comunicação. "O trabalho do pesquisador metapórico [é] o de acompanhar todo o desenvolvimento [do assunto] e observar os impactos e as mudanças que estariam ocorrendo no comportamento das pessoas [...] sentir [...] como se dá o jogo entre esses múltiplos atores" (Marcondes, 2012, p. 768).

Em breves palavras, o estudioso acompanha o movimento dos atores, inclusive ele mesmo; sente as manifestações públicas; ouve o que se diz em sua volta; procede à leitura dos jornais; "vasculha tudo o que está se falando a respeito na internet" para "caracterizar o processo comunicacional em andamento" (Marcondes, 2012, p. 769). A proposta de estudo se resume em colocar a questão da "qualidade da comunicação", se ela apenas deu alarme, ou "interferiu nas opiniões e nos comportamentos sedimentados, promovendo uma notória alteração das sensibilidades, das posturas e dos comportamentos, criando novos sentidos" (Marcondes, 2012, p. 773).

O coroamento do esforço é aleatório, pode ou não ocorrer, dependendo do que lhe declararem os informantes, mas, sobretudo, do que acontece com ele próprio. "O pesquisador observa o outro, seja o outro próximo, que a seu lado 
assiste às notícias e se deixa ou não impressionar por elas, seja o outro distante, as reações registradas pela comunidade [...]". O principal, no entanto, é que "o estudioso desloque-se nomadicamente por esses territórios à cata de sinais indicativos importantes", que ele "passeie, vagueie, ande em rodeios e descreva o Acontecimento comunicacional que se realizou num pequeno círculo" (Marcondes, 2009, p. 39).

"A produção de sentido ocorrida num exato momento" que, nesta altura, pode se dar, entretanto não se confunde com o sentido corrente ou que podem lhe atribuir os atores, ele incluído. “A comunicação é, antes de tudo, um acontecimento de natureza estética e o estético tem livre curso na mente das pessoas exatamente porque consegue driblar a barreira do racional” (Marcondes, 2012, p. 771). 0 sentido que importa, portanto, é o sentido surpreendente e inexplicável, seja na percepção do pesquisador, seja como entrevisto na experiência do informante, mas sempre "diferente para cada pessoa" (Marcondes, 2012, p. 771).

\section{Pesquisa ou escrita criativa?}

Ciro Marcondes nos informa que uma nova moda, uma nova seita, uma nova conduta sexual, como um velho filme, um velho livro ou uma velha música, revisitados, "têm potência para fazer trepidar todo um edifício de instituições, normas e valores sociais" (Marcondes, 2012, p. 772). Sem nos fornecer hipóteses a respeito de como e por que pode ser assim, nem sobretudo discriminar o que, exemplificando, escaparia ao processo, todavia sustenta, assim, um decisionismo potencialmente tão tolo quanto autoritário.

“Ninguém sai ileso após uma verdadeira comunicação. Se sair ileso, é porque a comunicação não se efetivou" (Marcondes, 2008, p. 36). Ocorre que, se é deste jeito, sabe-se de antemão sempre o que ela é e não é, não há razão para pesquisá-la. 0 teórico marcondiano estabeleceu-lhe a verdade, e sempre que, em meio ao contínuo atmosférico midiático, alguém se sentir lesado, talvez sequer seja 
preciso consultá-lo, para se ter confirmação de que o fato foi comunicacional. 0 sentido é e sempre será único e privado.

Para o autor, o pesquisador não tem que compreender ou atribuir significado ao que lhe comunica ou ele, em campo, comunica ao outro, pois o sentido construído em cada pessoa “é insondável” (Marcondes, 2012, p. 771): ele apenas "constata que uma nova ordenação é dada a uma situação, a um processo e que isso é sintoma da transformação da pessoa" (Marcondes, 2012, p. 771). Mas que ordenação é esta e como se sabe que é dela que se trata, sendo decidida introspectivamente?

Destarte, não surpreende que, aproximada nessa perspectiva, a conclusão de uma pesquisa em comunicação, nos termos do autor, seja um testemunho psicológico idealmente formatado com escrita criativa e inicialmente destinado apenas para o próprio sujeito:

A apresentação dos resultados só pode ser um relato vivencial do acontecimento, dotando-o de todos os detalhes da ocorrência [vivida pelo pesquisador], para que um leitor possa construir, ele mesmo, suas deduções a respeito da qualidade da comunicação produzida pela imprensa no momento do Acontecimento e, na medida do possível, revivê-lo, ao estilo das narrativas literárias, como se ele próprio o estivesse vivendo e sentindo. (Marcondes, 2012, p. 773).

A etapa do relato, função da competência narrativa de quem vivenciou o acontecimento em si ou no outro, é um esforço "para repassar ao leitor a força, o ânimo, a vitalidade, em suma, a vida do evento comunicacional" (Marcondes, 2010a, p. 274). A contradição performativa é o fantasma que assombra aqui, porque se a comunicação é algo que ocorre uma única vez, o que se passa ao leitor, havendo sorte, é a chance de fazer outra experiência, e não um conhecimento do que se pretende relatar.

Questionamos, no entanto, se, em sendo assim, não seria melhor pregar ao curioso em saber sobre a comunicação humana o consumo de boa literatura e obras cinematográficas? Nosso juízo é afirmativo: a pesquisa, neste contexto, se 
torna dispensável em comparação com o exercício literário e a fruição estética. Marcondes resgata a introspecção e a vivência empática, para justificar a construção de relatos descritivos cuja significação, considerando os exemplos dados, é, em geral, banal. A trivialidade dos resultados concretos nos deixa a suspeita de que o saber comunicacional, se é que pode ser narrado, tem um cunho que, em nosso juízo, lhe priva de relevância para os outros ${ }^{4}$.

Marcondes e colaboradores desejam:

Conhecer o que a vivência das manifestações produz em cada pessoa que sai às ruas ao acompanhar a marcha de protesto. Que estranho processo interno se desenvolve quando a pessoa troca seu quarto, sua sala, seu escritório, onde ficava o tempo todo diante de uma tela, pela rua, inicialmente para assistir à passagem do povo gritando palavras de ordem, depois misturando-se a ele, caminhando junto, fazendo uma verdadeira imersão no fluxo humano. (Marcondes, 2015, p. 2).

A estranheza, contudo, não é distinta, por exemplo, da provocada pela mãe que, ouvindo o choro do bebê ou a explosão provinda da cozinha, para às pressas de ver sua novela, para atender o ocorrido. Vale o mesmo para a conclusão geral que daquele fato tira o autor, sentenciando que, em um e outro caso, "efetivamente, há um choque, uma quebra, um 'click', que coloca o observador na posição de cobaia. Nós nos observamos observando a massa que passa [como a mãe que sai em sobressalto]. Nós sentimos a diferença, nós sentimos mudança" (Marcondes, 2015, p. 2). Não é tudo isso óbvio e genérico?

\footnotetext{
4 Marcondes, coerente em nosso ver, só reporta experiências de pesquisa em termos hipotéticos (Marcondes, 2014a; 2012). O cunho anedótico e, via de regra, irrelevante do emprego de sua teoria na pesquisa se constata nos vários trabalhos de seus orientandos. "As pessoas são mais parecidas comigo do que eu jamais poderia imaginar", parece ser a principal constatação da autora de um relato. "Ir aos protestos de rua foi um ótimo exercício para treinar em não julgar os outros, suas diferentes posições políticas e reivindicações", aprendeu uma outra autora. Saber que alguns visitantes de uma exposição fotográfica "muitas vezes olhavam a fotografia com neutralidade, mas quando liam a legenda seus rostos automaticamente mudavam", foi a descoberta que espantou um terceiro investigador, etc. (Marcondes, 2015; 2010c). Redime esta série de platitudes, talvez, a ressalva de que, a exemplo do acontecimento comunicacional, também os relatos a respeito são, em seu conteúdo proposicional, efêmeros e não transmissíveis.
} 
$\mathrm{Na}$ origem do problema se encontra o fato de, nesta epistemologia, o meio de pesquisa não ser um método de análise ou interpretação, mas a intuição sensível, a pré-disposição à apreensão imediata e instantânea de um momento revolucionário em relação às intuições intelectuais que o precedem e a sucederão. 0 resultado é um discurso analítico existencial, em que a comunicação, conforme evidencia o conjunto da obra, termina por se diluir no indeterminado.

Na investigação da comunicação, não cabe a procura de um agente causador, pois as coisas não se dão dessa maneira; há todo um jogo entre os participantes, onde entram estratégias de captura, comportamentos de sedução e de contra sedução, apresentando o social como um sistema de ações variadas e imprevisíveis, de estabilizações e de rupturas, de encaixes e desencaixes, vantagens eventuais e perdas de posição. (Marcondes, 2010a, p. 271).

Das dezenas de autores que estuda, Marcondes só tira, para argumentar em favor de sua teoria, os enunciados triviais e juízos analíticos, as regras para a condução do espírito e uma doutrina acerca do inefável (ver, por exemplo, 2010a, p. 199-200). Falta-lhe a percepção de que enunciados como o acima citado, presentes em toda sua obra, valem para quaisquer coisas e, portanto, não bastam para especificar uma teoria da comunicação. A caracterização do terreno de investigação como emaranhado de fios, vetores, linhas, correntes e cruzamentos, tanto quanto da nossa presença nele como deslocamento nômade, errático, em rodeio, remete a intuições puras da razão, que, embora possam orientá-lo, não são conhecimento, ao não definirem coisa alguma. Elas se prestam ao conceito de comunicação, como a tudo o mais que se desejar, mas só lhe abrem o conhecimento abstrato ou singular, vedando o âmbito do específico e concreto.

A percepção de que algo mudou, houve uma mudança na situação, à falta de critérios indicativos de relevância, implica não só que qualquer ente não percebido possa ser identificado como a novidade, um "conhecimento", mas que, de acordo com a percepção, tudo passe a ser mudança, consubstanciando o princípio de que 
"o mundo é permanente movimento" da vasta construção abstrata e solipsista que é esta nova teoria da comunicação (Marcondes, 2010a, p. 247).

Marcondes faria melhor, cremos, explicitando a seu leitor que, ao reivindicar papel na atividade de pesquisa, sua teoria se reveste de um cunho introspectivo, em vez de lógico, mas também que, em sendo assim, seu caráter é virtualmente retórico, para um auditório livre da sua mística. Apelando ao princípio da causa ausente, o argumento remete a uma espécie de deusa spinozista, visto que, embora possa estar em toda a parte, a comunicação, tal como a nova teoria a entende, se dá arbitrariamente.

Em sua obra, a teoria sabe de antemão o que a comunicação significa, isto é, experiência única e irrepetível, mas só a aprende na pesquisa através dos seus efeitos, cuja cognição, em sendo, por definição, singular, não pode nem se vê razão para ser compartilhada. A procura de causas específicas é preterida em favor da abdução puramente intuitiva e arbitrária, visto que se é a mudança no estado de coisas do participante que define a ocorrência da comunicação, se pode chegar às causas toda a vez que se pesquisa e se deseja: salvo argumento específico em contrário, sempre está havendo alguma mudança, se partirmos, como é o caso em juízo, de premissas heraclitianas.

Ao autor, de resto, escapa o fato de que o efeito, a mudança, não é a comunicação mesma e, portanto, sua teoria, apesar de postular a singularidade do acontecimento, não logra escapar da definição a priori: a comunicação é sempre evento singular, o que encobre uma falácia lógica. Afinal de contas, se a comunicação é, a cada vez, um evento único e irrepetível, como reza a teoria, ninguém não apenas teria como afirmar na pesquisa concreta o que é seu efeito: pode ser qualquer evento anterior, algo que o autor concordaria; mas não teria como afirmar que tem a ver com comunicação, o que ele passa por alto, pois o acontecimento também poderia ser revelação divina, insight psicológico, sinapse cerebral, acesso de loucura, etc. 
A atribuição de um cunho comunicacional ao ocorrido é pura petição de princípio, na medida em que, concebendo o evento como ato sui generis, sua teoria da comunicação carece de um conceito de ação capaz de lhe hipotetizar um sentido concreto e, assim, tornar-se relevante na investigação. 0 autor reconhece que está propondo uma "ciência do transitório", que capta o momento, mas não tira daí as lições ou a devida reflexão, pois se "o acontecimento só pode ser percebido no instante em que as linhas intencionais coincidem ao se cruzar, em que a dinâmica dos agentes constrói o ato" (Marcondes, 2010a, p. 195), não se vê razão para expôlas. $\mathrm{O}$ acontecimento não comporta protocolo, apenas experiência e por isso não se trata aqui de método, muito menos de ciência: trata-se, em suma, de uma doutrina de ordem estética orientada no sentido do aconselhamento alheio.

\section{Conclusão}

Marcondes confia aos estudos de comunicação a tarefa de "sentir as vibrações de seu acontecimento, sua força, sua energia própria, e encontrar uma forma de apresentá-las ao outro, de repassá-las, de manter os efeitos vibrando" (Marcondes, 2010a, p. 194). A explanação cabe aos estudos paracomunicacionais, feitos pelas demais ciências humanas. Os estudos comunicacionais seriam essencialmente pontuais e descritivos; seu objetivo, relatar as transformações operadas pelo evento comunicacional "tanto em indivíduos isolados como em fenômenos sociais de maior alcance" (Marcondes, 2010a, p. 194).

Ocorre que deste jeito, parece-nos passar despercebido ao autor que, definindo os acontecimentos comunicacionais por sua imprevisibilidade, unicidade, instantaneidade e ausência de substância, já que toda caracterização qualitativa implicaria em sua subordinação ao conhecimento paracomunicacional, a nova teoria se tranca em uma doutrina asséptica, virtualmente vazia, cujos apelos à "pulsação da vida", na melhor das hipóteses, só tem sentido retórico. 
Há que pensar que se o cunho de eterno percurso dado por Marcondes à nova forma de estudar a comunicação não é fruto de um raciocínio filosoficamente banal que, afirmando a virtude de se deixar tudo em aberto e não se comprometer com a busca de iluminação, em nome da ânsia interminável pela experiência, não chega a nada significativo que não seja solipsístico e, assim, se impede de compartilhar qualquer conhecimento. 0 autor nos propõe uma teoria pura cujo estatuto na pesquisa, se esta tivesse propriedade e relevância, seria essencialmente introspectivo, esforçando-se muito além da conta para, em última análise, brigar por definições cujo alcance, do ponto de vista do filosófico é discutível e, do ponto de científico e acadêmico, nos parece nulo.

Cremos que, considerando com mais atenção a "Crítica do Juízo" de Kant, ele concluiria dizendo que a comunicação, conforme a define, embora mereça ser pensada, não pode ser estudada, nem constitui um objeto de pesquisa no sentido acadêmico e científico; ou que, embora sendo, como sugere, o que de mais importante talvez reste em uma Sociedade Frankenstein, é ela algo que ninguém jamais deveria tentar referir, visto que "o que não pode ser dito, dever ser calado", como escreveu Wittgenstein (1968 [1921], p. 129) ${ }^{5}$.

\section{Referências bibliográficas}

DEWEY, John. Experiência e natureza. São Paulo: Abril, 1915-1974. (Coleção Os Pensadores, v. 40)

KANT, Immanuel. Crítica da faculdade do juízo. Rio de Janeiro: Forense-Universitária, 1790-1983.

$5 \quad$ Revisando o texto para publicação, fizemos leitura de artigo relevante, contendo muitos pontos de convergência com o argumento desenvolvido nestas páginas (Marques; Martino, 2018). 
KATZ, Chaim. Poder, culpa e angústia da filosofia: o problema da comunicação na obra de Husserl. In: Revista de Cultura Vozes, Petrópolis, v. 66, n. 8, p.47-55, 1972.

MARCONDES, Ciro. O capital da notícia. São Paulo: Ática, 1986.

(Org.). Pensar, pulsar. São Paulo: NTC/Brazil, 1996.

Cenários do novo mundo. São Paulo: NTC, 1998.

O escavador de silêncios. Nova Teoria da Comunicação. São Paulo: Paulus, 2004. v. 1.

Até que ponto, de fato, nos comunicamos? São Paulo: Paulus, 2007.

Comunicação, uma ciência inexata e, contudo, rigorosa. In: CASTRO, G. et al. (Orgs): Os saberes da comunicação. Brasília: Casa das Musas, 2008.

Até hoje ainda não começamos a estudar a comunicação. In: Communicare, São Paulo, v. 9, n.1, p. 33-40, 2009.

(Org.). Transporizações. São Paulo: ECA/Filocom, 2010.

- O princípio da razão durante: o conceito de comunicação e a epistemologia metapórica. Nova Teoria da Comunicação. São Paulo: Paulus, 2010a. v. 3, t. 5.

O princípio da razão durante: comunicação para os antigos, a fenomenologia e o bergsonismo. Nova Teoria da Comunicação. São Paulo: Paulus, 2010b. v. 3, t. 1

Por que a Nova Teoria é uma forma diferente de se pesquisar o jornalismo. In: Revista Famecos, Porto Alegre, v. 19, n. 3, p. 759-774, 2012.

O rosto e a máquina. Nova Teoria da Comunicação. São Paulo: Paulus, 2013. v. 1.

. A nova forma de pesquisar a comunicação. In: FRANÇA, V. et al. (Orgs.): Teorias da comunicação no Brasil. Salvador: Edufba, 2014a.

__ (Org.). Dicionário de Comunicação. 2. ed. São Paulo: Paulos, 2014b.

De como a comunicação choca, revela, nos traz de volta ao mundo. In: E-Compós, Brasília, v. 18, n.1, p. 1-12, 2015.

Comunicologia ou mediologia? São Paulo: Paulus, 2018.

. Hora de reescrever as teorias da comunicação. In: Questões Transversais, São Leopoldo, v. 7, n. 14, p. 4-12, 2019.

MARQUES, Ângela C. S.; MARTINO, Luís Mauro de Sá. Duas perguntas metodológicas à Teoria do Acontecimento Comunicacional. In: Oliveira, Danielle; Liesen, Maurício (Orgs.):

Dossiê Crise, Feminismo e Comunicação - https://revistaecopos.eco.ufrj.br/

ISSN 2175-8689 - v. 23, n. 3, 2020

DOI: 10.29146/eco-pos.v23i3.27433 
Para comunicar o incomunicável: Escritos em homenagem a Ciro Marcondes Filho. São Paulo: Paulus, 2018.

SCHÉRER, René. Philosophies de la communication. Paris: Sedes, 1971. 